\title{
COORDINATION OF COMPOUND ASCIDIANS BY EPITHELIAL CONDUCTION IN THE COLONIAL BLOOD VESSELS $†$
}

\author{
G. O. MACKIE AND C. L. SINGLA
}

Biology Department, University of Victoria. Victoria, British Columbia, V8W 2 Y2

\begin{abstract}
Bursts of electrical potentials propagate at $c a .2 .0 \mathrm{~cm} \mathrm{~s}^{-1}$ within the colonial vascular system of Botryllus, Botrylloides, and Metandrocarpa, serving to coordinate contractions of the vascular ampullae and mediating protective closure and ciliary arrest in zooids. Nerves are absent from the vessels and ampullae. Impulses are presumed to propagate from cell to cell in the vascular epithelium via gap junctions, shown to be present by electron microscopy.
\end{abstract}

\section{INTRODUCTION}

Colonial ascidians of the Family Styelidae produce zooids by budding as described for Botryllus (Berrill, 1941; Sabbadin, 1955) and for Botrylloides (Berrill, 1947). The buds, instead of separating as in most ascidians, remain permanently attached via the vascular system which consists of an elaborate colony-wide network of blood vessels, details of which are given by Brunetti and Burighel (1969). Blindending swellings, or ampullae, are produced at various points, chiefly around the edges of the colony (Figs. 1, 2). Regular cycles of expansion and contraction occur in these ampullae causing a tidal ebb and flow of blood within the connecting vessels, as first described by Bancroft (1899). Bancroft noted that as many as 50 ampullae within an area of about 4-5 $\mathrm{mm}^{2}$ can exhibit coordinated contractions. Contractions occur not only in the ampullae, but in the blood vessels as well (Mukai et al., 1978). Contraction is attributable to bundles of microfilaments in the epithelial cells forming the vascular walls (DeSanto and Dudley, 1969) but the mechanism responsible for coordination has not been satisfactorily explained. Bancroft's observations suggested variations in blood pressure as the principal means of coordination, as did those of DeSanto and Dudley (1969). However, Mukai et al. (1978) found that coordination could best be explained on the assumption that signals of some kind are conducted along the vessels. As nerves have never been described in the vessels, these workers proposed epithelial conduction as the signalling mechanism. This possibility was also advanced by V. L. Scofield (pers. comm.) on the basis of her observation that ampullar rhythms of recenty settled larvae immediately come into synchrony when the larvae undergo fusion. Torrence and Cloney (1981) favored epithelial conduction as the probable basis for coordination of ampullae in Molgula, and showed that gap junctions are present between the living cells.

The present study demonstrates that electrical impulses propagate throughout the vascular network and ampullae, and shows that these signals are not only responsible for coordination of ampullar rhythms but also serve to coordinate protective responses of the interconnected zooids.

Received 21 February 1983; accepted 23 May 1983.

† Dedicated to N. J. Berrill on the occasion of his 80th birthday, April 6th, 1983, in appreciation of his many important contributions to tunicate biology. 


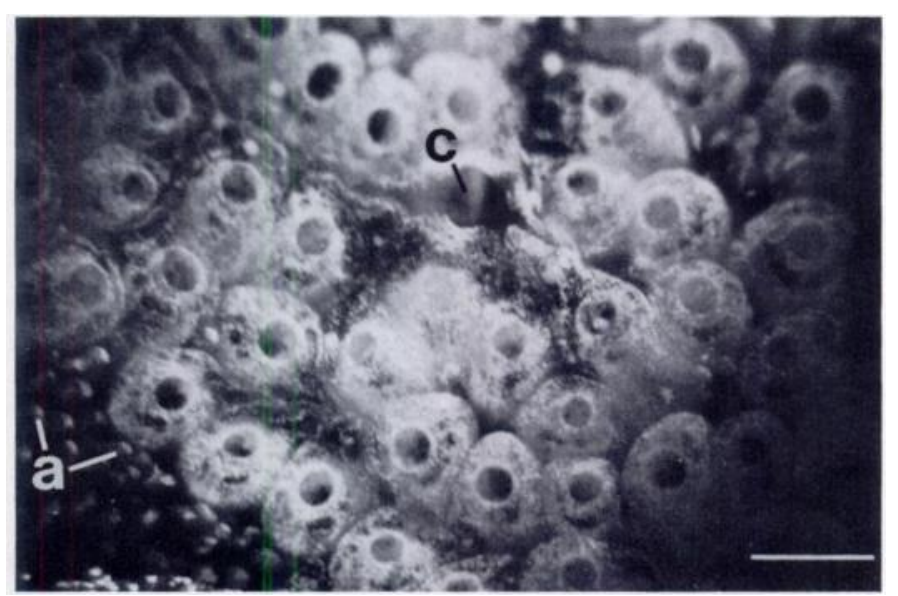

FIGURE 1. Edge of a colony of Botrylloides. a, ampullae; c, common cloacal siphon. Bar represents $1 \mathrm{~mm}$.

\section{MATERIALS AND METHODS}

During February and March 1982 colonies of Botryllus sp. (the "Monterey Botryllus" of Scofield et al., 1982) and Botrylloides diegensis were collected from rocks in Monterey Bay, California and maintained in the sea water system at the Hopkins

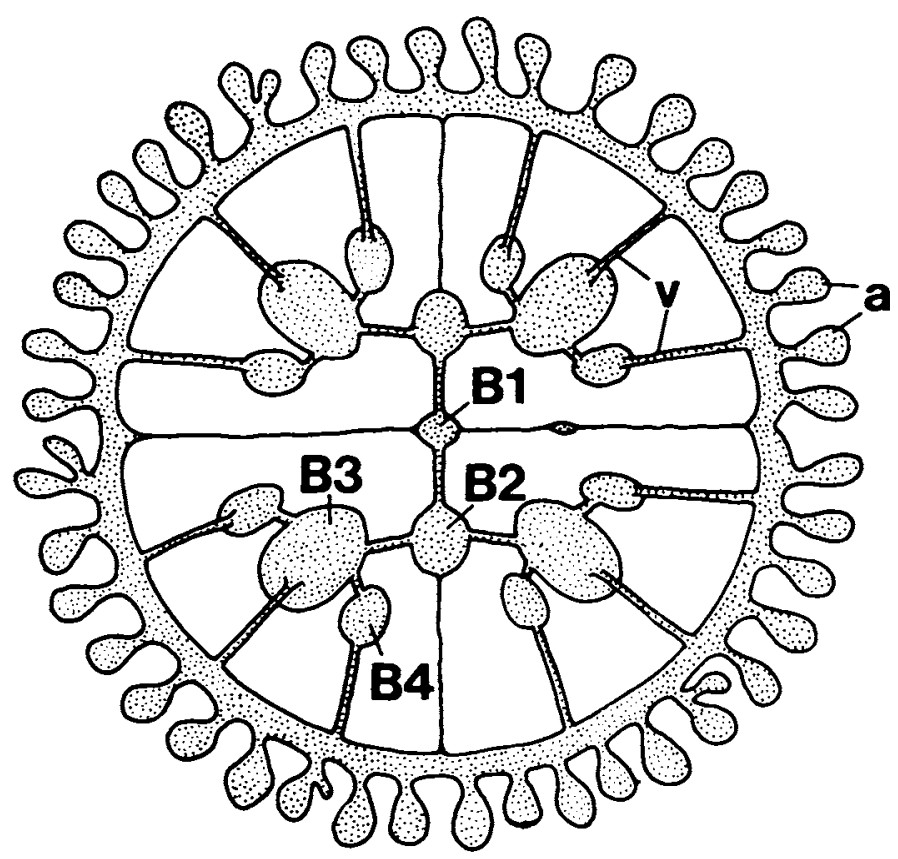

FIGURE 2. Scheme showing the circulatory system and zooid interrelationships in a young colony of Botryllus. a, ampullae; B1-B4, first four generations of blastozooids; v, connecting vessels (from Brunetti and Burighel, 1969). 
Marine Station. Larvae were settled and grown on glass or plastic sheets. Dr. D. P. Abbott made available a colony of Metandrocarpa taylori found growing in a water table in the basement of the Agassiz Building.

Botryllus specimens were fixed in $4 \%$ glutaraldehyde in $0.2 \mathrm{M}$ cacodylate buffer (pH 7.4) for one hour at room temperature, rinsed in the cacodylate buffer and post fixed in $1 \%$ osmium tetroxide in the same buffer for one hour at $4^{\circ} \mathrm{C}$. The material was rinsed with distilled water, dehydrated progressively in acetone, transferred to propylene oxide, and embedded in Epon 812. Thin sections were stained wth uranyl acetate and lead citrate and were examined in Philips EM 300.

Botrylloides larvae were fixed while attached to acetate sheets. The acetate dissolved in the acetone used for dehydration.

For the electrophysiological recordings, fine polyethylene suction electrodes (30$50 \mu \mathrm{m}$ I.D.) were used. Recorded potentials were amplified and displayed on a Tektronix storage oscilloscope and on a Brush chart recorder. A thermistor flow meter was used to detect variations in siphonal currents.

\section{RESULTS}

\section{Fine structure}

We have examined Botryllus and Botrylloides to 1) determine if nerves are present in the vascular vessels and ampullae, and 2) to confirm that the junctional specializations reported by Torrence and Cloney (1981) for Molgula are also to be found in our species.

Except for the specialized glandular cells of the ampullar tips ("pad cells", Katow and Watanabe, 1978) the cells forming the vascular lining are of a single type equivalent to the "parietal cells" of Torrence and Cloney (1981). These cells may be columnar or squamous depending on the state of contraction at the moment of fixation. Their inner borders become somewhat folded in the contracted state (Fig. $3 a)$, and a layer of micro-filaments can be seen running close beside the luminal border, as first noted by DeSanto and Dudley (1969). Nerves have not been seen in any part of the system.

Tight junctions (zonulae occludentes) are located at the outer ends of the line of apposition between adjacent cells (Fig. 3a, c). These junctions are of the punctate type common in tunicates. No such junctions occur on the inner (luminal) side. Gap junctions are seen at intermediate points along the line of apposition (Fig. 3b). The intercellular space along most of the line of apposition is about 15-20 nm wide, but in the gap junction, the two membranes are separated by about $2 \mathrm{~nm}$.

\section{General activity and responses to stimulation}

The following comments refer equally to Botryllus and Botrylloides. Colonies maintained in clean water pump water continuously through the branchial sac, showing occasional arrests of the branchial cilia along with siphon contractions when large particles strike the siphons. No regular pattern of ciliary arrests or muscular contractions was observed in the zooids. The hearts of the different zooids beat rhythmically at their own individual frequencies, reversing periodically. Peristaltic waves pass along the gut, and feces are eliminated at regular intervals.

Movement of blood is not confined to the zooids but takes place throughout the colonial vascular network. The vascular ampullae associated with these vessels can be seen swelling and contracting rhythmically. In newly settled zooids and in larger colonies as noted by Bancroft (1899) contractions of the ampullae are syn- 


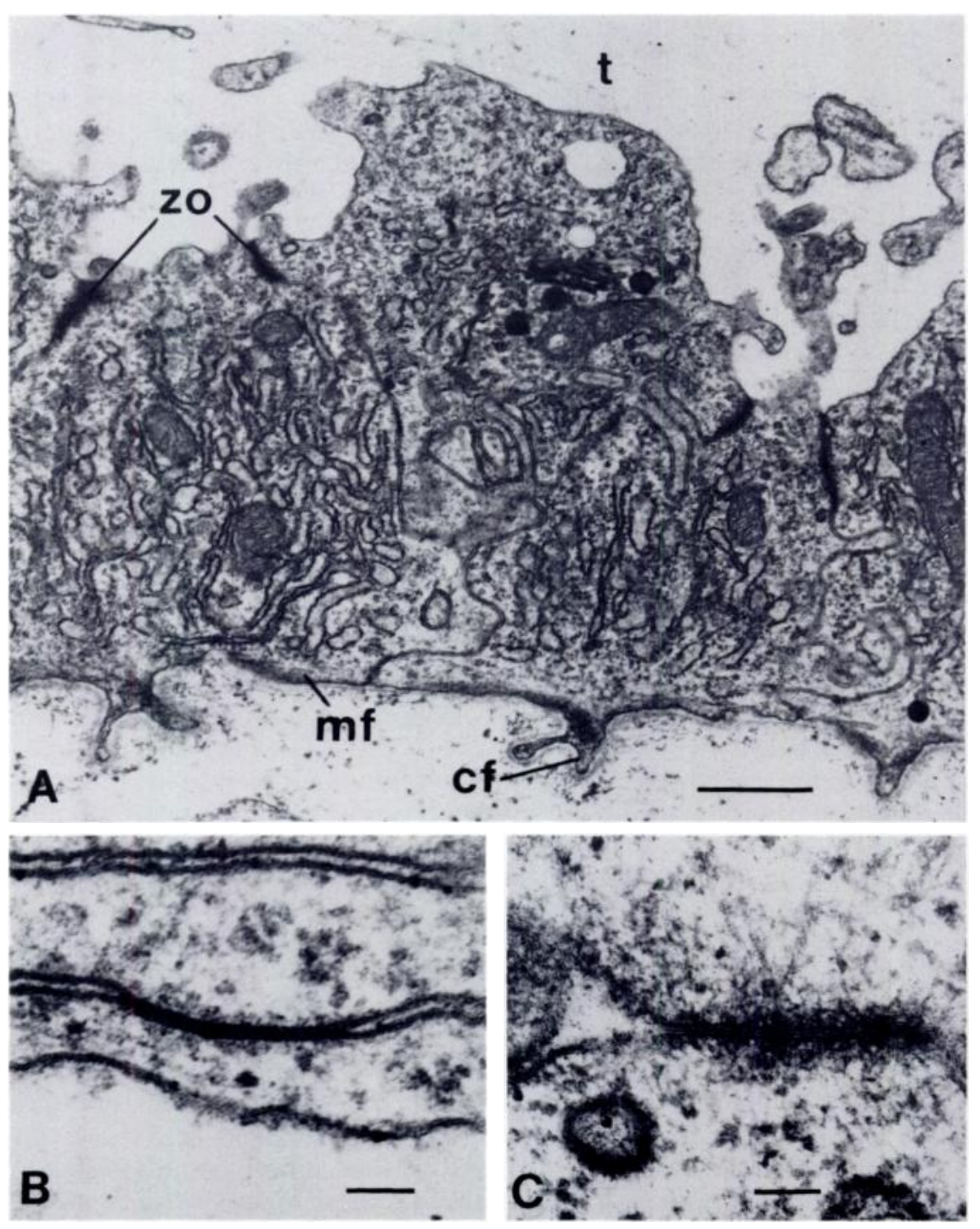

FiguRE 3. Fine structure of parietal cells forming the ampullar wall in Botrylloides. (A) shows several partially contracted cells. On the inner side, contractile folds ( $\mathrm{cf}$ ) are seen, and microfilaments (mf) lie against the membrane. On the outer side, next to the tunic (t), the cells are joined by zonulae occludentes (zo). (B) shows a gap junction between two parietal cells and (C) shows detail of the zonula occludens. Bar in (A) is $1 \mu \mathrm{m}$, in (B) and (C) $0.1 \mu \mathrm{m}$.

chronized. Blood flow through the colonial vascular network appears to be due chiefly to the contractions of the ampullae, and is affected only locally by the actions of the hearts of the zooids. Bancroft (1899) showed that the rhythmic flushing of blood through the vascular network continued in anaesthetized colonies after the hearts of the zooids had stopped beating, and that coordinated ampullar contractions persisted in regressive colonies after the zooids had degenerated. In the present study, regular, synchronized ampullar contractions were seen in strips cut from the edge 
of a colony which contained no zooids. Torrence and Cloney (1981) showed that individual ampullae, when isolated, continued to pulsate rhythmically.

In intact colonies, contractions of the ampullae drive blood into the zooids, causing them to swell (DeSanto and Dudley, 1969). The slow rising and falling of the surface of the colony allows results to be recorded with flow meters placed over the oral or cloacal siphons. Each time the colony swells, the siphons are brought nearer to the sensor and a surge in flow rate is recorded (Fig. 4A). Short term changes in flow rate due to siphon contractions or ciliary arrests do not affect the overall rhythm, which is manifested throughout the whole colony, or large parts of it. Coordination was demonstrable in one colony over a distance of $1 \mathrm{~cm}$.

When the surface of a zooid is touched lightly with a needle, the zooid contracts its oral siphon and its portion of the common cloacal passage, while the branchial cilia show a brief arrest. Slightly stronger stimulation causes contractions and ciliary arrests in adjacent zooids within the same group ("system") sharing a common cloacal opening. Spread to adjacent systems takes place with still stronger or repetitive stimulation. Spread appears to occur more readily within a system than between systems, regardless of proximity to the site of stimulation. When excitation reaches a new system several zooids usually contract together almost synchronously, rather than in a wavelength-like sequence. These observations suggest that contrac-
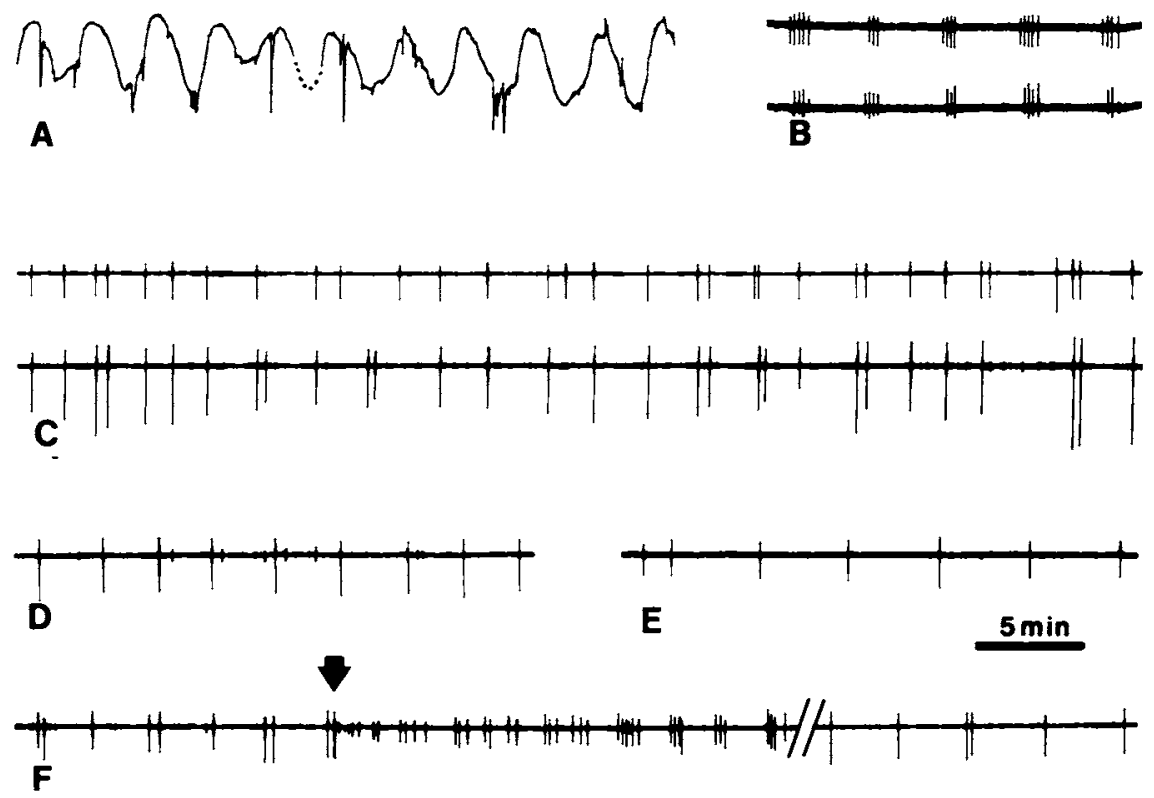

FIGURE 4. Ampullar rhythms monitored with a flow meter (A) and electrically (B-F). (A) Botrylloides: variations in water flow past sensor placed over cloacal siphon as colony rises and falls (retouched to remove artefacts). (B) Botryllus: electrical record of multiple NP bursts from two ampullae, $2 \mathrm{~mm}$ apart. Although contractions were perfectly syncrhonized the number of NB bursts at each contraction varied at the two sites. (C) Botrylloides: NP burst record from two points $1.5 \mathrm{~cm}$ apart, in a large colony. Most but not all contractions are synchronized at the two sites. (D) Botrylloides: NP bursts from an ampulla of a recently settled larva (cozooid). (E) Metandrocarpa: NP bursts from an ampulla. (F) Botrylloides: ampullar NP burst record. At the arrow, a scalpel blade was drawn along near the edge of the colony separating a group of about 200 ampullae, including the one with recording electrode attached, but excluding all zooids. Activity is shown immediately after the cut, and after a break in the record lasting $18 \mathrm{~h}$. The $5 \mathrm{~min}$ bar applies to all records. 
tions are probably not mediated mechanically, but instead are due to impulse conduction. This conclusion is further supported by the observation that zooids can be made to contract by stimulation of nearby ampullae. The responding ampulla moves so little that a mechanical effect on adjacent zooids is scarcely conceivable.

The effects of electrical stimulation resemble those produced by tactile stimulation. Colonies adapt readily to maintained stimulation. A stimulus which would cause a spreading response in a rested colony may cause only a small local response after the colony has been stimulated for a period of time.

\section{Electrical monitoring of ampullar rhythms}

Suction electrodes attached to ampullae or zooid walls pick up a rapid burst of potentials, or several such bursts, each time the ampullae contact. Monitoring from the ampullae is preferable, as an electrode on the zooid wall picks up ciliary arrest potentials as well as the events correlated with ampullar contraction. These events are termed network potentials (NPs) as they propagate throughout the vascular network interconnecting the ampullae and zooids. NPs characteristically occur in short bursts. Recorded at slow chart speeds, these bursts appear as single events (Figs. 4B-F). This method of monitoring ampullar rhythms is very simple, and causes minimal disturbance to the colony. The NP burst coincides with the start of the ampullar contraction phase. As many as five bursts (each consisting of several individual NPs) may accompany a single contraction (Fig. 4B). The larger numbers are typical of colonies subjected to damage or overstimulation. Rested colonies maintained in slowly running water usually show only one NP burst at each contraction. Recordings from two ampullae within the same colony show coordination of ampullar rhythms, although in large colonies ( $<1.0 \mathrm{~cm}$ wide, as in Fig. $4 \mathrm{C})$ some loss of coordination may be apparent. In six colonies of Botrylloides, contractions occurred at mean intervals of $2.2-4.0$ minutes $(\overline{\mathrm{X}}=2.6, \mathrm{SD}=0.6 \mathrm{~min}$ overall). Values for Botryllus fell within the same range (Fig. 4D). Records from Metandrocarpa gave a mean value of 4.2 min (Fig. 4E).

While the NP burst lasts less than a second, the contraction phase of the ampullar cycle lasts for more than a minute. It appears that the NP burst is essentially a triggering event serving to initiate contractions simultaneously throughout the network. Electrical or mechanical stimulation, or damage, evokes NP bursts and may reset the ampullar rhythm, and alter its pattern, as seen in Figure 4F.

\section{Generation and conduction of network potentials}

The composite nature of the NP burst is readily observed when the burst is displayed at higher sweep speeds on the oscilloscope, but the component potentials are not well resolved in suction electrode recordings, but merge into an irregular wave. In the clearest recordings the event can be broken down into about 6-8 separate potentials, 50-70 ms apart. No two bursts are the same, and the same burst may show different time relationships when recorded at two different places (Figs. $5 \mathrm{~A}, \mathrm{~B}$ ). Initial attempts by the first author to insert glass microelectrodes into the epithelial cells forming the wall of the ampullae were unsuccessful, but later $\mathbf{A}$. N. Spencer succeeded in obtaining an intracellular recording of an action potential of duration $\mathrm{ca}$. $50 \mathrm{~ms}$, rising from a $48 \mathrm{mv}$ resting potential (Fig. $5 \mathrm{C}$ ). The thinness of the epithelium and the lack of firmness of the tissue generally makes microelectrode work difficult in this material. The one successful recording was of brief duration, and probably provides a somewhat attenuated version of the spike. Though 


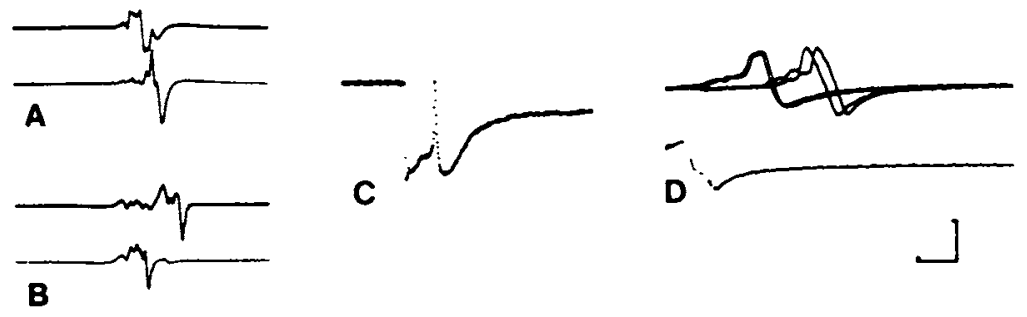

FIGURE 5. Network potentials (NPs) recorded from ampullae of Botryllus (A, B, D) and Botrylloides (C). (A), NP burst recorded at two different ampullae in a 2-zooid colony. (B), same preparation as in (A), another NP burst. (C), intracellular recording of a single NP. (D), time relationships within an NP burst. Triggering from the lower trace reveals two sets of NPs within a single burst in terms of wave form and arrival time on upper trace. Bars represent $500 \mu \mathrm{v}, 200 \mathrm{~ms}$ in (A) and (B), $20 \mathrm{mv}, 200 \mathrm{~ms}$ in (C) and $1 \mathrm{mv}, 50 \mathrm{~ms}$ in (D).

preliminary in nature, this result does confirm that the ampullar wall is the site of impulse conduction. Taking into account the absence of nerves, and the presence of gap junctions we can conclude that the excitable elements are the cells of the vascular epithelium itself.

Measurement of conduction velocities is hampered by the irregular configuration of the vascular network along which the signals are conducted and by the composite nature of the NP itself. Values ranging from $0.5-1.9 \mathrm{~cm} \mathrm{~s}^{-1}(\overline{\mathrm{X}}=0.9 . \mathrm{SD}=0.59)$ have been obtained. The distances between the electrodes in these experiments were measured directly and no allowance was made for deviousness in the actual conduction pathways. The highest velocity values were obtained from strips near the margin of the colony where a major vessel runs circumferentially (Fig. 2), and the electrodes were placed along this line. Thus, the 'true' conduction velocity is probably close to $2 \mathrm{~cm} \mathrm{~s}^{-1}$.

As noted above, simultaneous recordings from two ampullae in the same general vicinity show differences in the time relationships of bursts arriving at the two sites (Figure 5A, B) as well as in the numbers of potentials comprising the bursts, and the intervals between them (Fig. 4B). It seems likely that bursts are produced by interaction of many different pacemaker sites. Figure 5D shows an example of an apparent shift in the pacemaker site during the course of a single burst.

\section{Coordination of protective responses in the zooids}

Like a number of other ascidians, both compound and solitary (Mackie, 1974, Mackie et al., 1974) botryllid zooids show characteristic, large potentials when stimulated, termed ciliary arrest potentials (CAPs). The CAP system is under nervous control from the brain. Muscles in the siphons and mantle usually contract concurrently with ciliary arrest, but the potentials due to muscle contraction are small. Botryllids differ from other ascidians by showing a second major type of electrical signal in recordings from their zooids. These events appear indistinguishable from NPs recorded from the ampullae, and it is concluded that NPs are conducted through the vascular network, to the zooids. Here they may merge giving a composite irregular sort of electrical event (Fig. 6A) or remain recognizable as discrete events (Fig. 6B). Although the distances are small, conduction velocities have been measured in isolated strips of tissue cut from the surface of Botryllus zoooids between the oral and cloacal siphons. Such strips give NP conduction velocities in the order of $2.0 \mathrm{~cm} \mathrm{~s}^{-1}$. The NP conducting tissues in such strips have not been identified. 

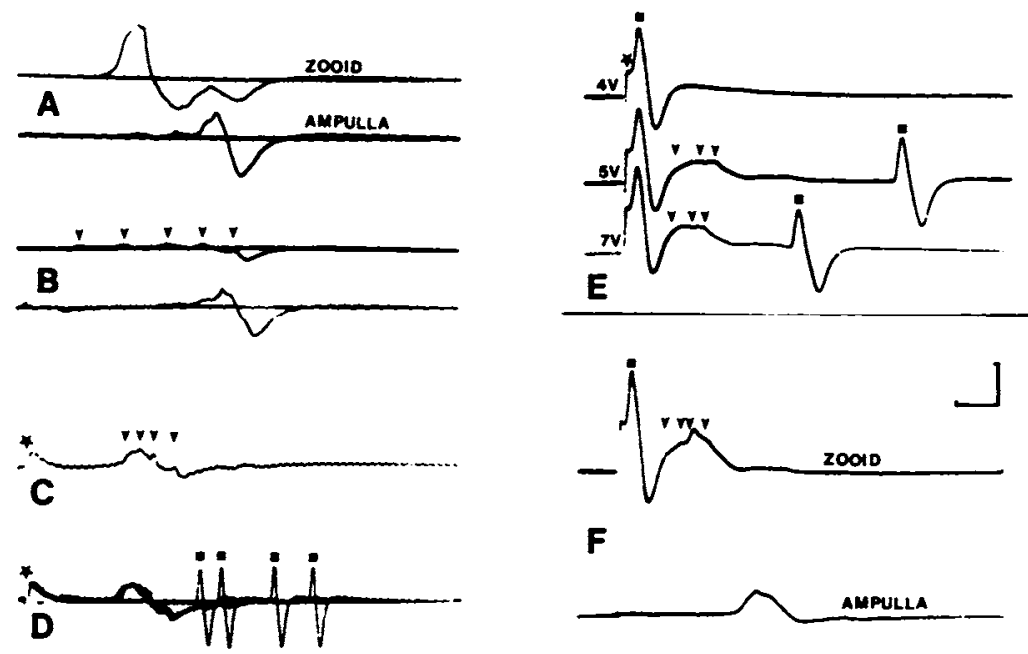

$\mathbf{F}$

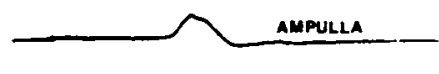

FIGURE 6. Two way transmission of NPs (arrow heads) between ampullae and zooids of Botryllus (A, B, E, F) and Botrylloides (C, D). (A), a tactile stimulus (needle prick) to an ampulla evokes a NP burst which propagates to a zooid causing it to contract and to another ampulla. (B), same as in (A), but spontaneous NP burst, for comparison. The zooid did not contract. (C), following a shock (asterisk) on a zooid an NP burst is recorded on another zooid. (D), same as in (C), several sweeps superimposed. The NP burst fails to reach the recording site on some occasions. NP bursts which do arrive trigger CAPs (spots) after variable latencies. (E), stimulating and recording on same zooid. With $4 \mathrm{v}$ shock, only a CAP is evoked. Stronger shocks caused repetitive firing of CAPs and triggered NP bursts. (F), same as in (E), but with a second electrode on an ampulla. The CAP does not spread to the ampulla, but the NP burst does. Bars represent $500 \mu \mathrm{v}, 50 \mathrm{~ms}$ in (A) and (B), $500 \mu \mathrm{v}, 100 \mathrm{~ms}$ in (C) and (D), and $1 \mathrm{mv}, 50 \mathrm{~ms}$ in (E) and (F).

They could be the blood vessels of the mantle, or the inner or outer mantle epithelia. No other organs were in the strips in question.

Stimulation of a zooid can evoke a NP burst which propagates to other zooids (Fig. 6C, D) and may trigger the usual effector responses (CAPs and muscle twitches) in them. There is a delay of at least $100 \mathrm{~ms}$ between the arrival of the NP burst and the production of the triggered events, which suggests that excitation passes into and through the central nervous system of the zooid before entering the ciliary and muscular effectors. It is not known how NPs, as epithelial events, enter the nervous system, but epithelio-neural transmission steps have been identified in other tunicates, e.g., Oikopleura (reviewed by Bone and Mackie, 1982). Stimulating the surface of a zooid at low voltage may evoke one or a series of CAPs, with muscle twitches, but slightly stronger shocks can evoke NPs as well (Fig. 6E). Both of these electrical events, CAPs and NPs, are evoked after delays indicating passage through the nervous system rather than being due to the direct action of stimulating current across the body wall. The delay is greater in the case of NPs, which might reflect the greater length of the motor pathway involved. NPs evoked in this way can propagate to other zooids and to ampullae (Fig. 6F). CAPs never spread outside the zooid they are evoked in, but they can be elicited indirectly in other zooids by propagated NPs (Fig. 6D).

NPs cannot spread between zooids by way of the upper surface of the colony, even though the mantles of the adjacent zooids are closely applied to one another 
in this region (Fig. 1). The routes in and out of zooids must lie deeper, and are presumably the vascular connections.

NPs do not always spread beyond the confines of a stimulated zooid, and they do not always enter zooids when spreading through the vascular network. When they do enter, they may or may not cause CAPs. Conduction barriers must exist. It seems likely, but has not been proven, that the time relationships and number of NPs in a burst is critical in overcoming these barriers. There is some evidence that conduction velocity declines within a burst. If so, the intervals between the pulses in a burst would increase with distance from the site of stimulation, which might account for activation of effectors in zooids near the stimulus, while distant ones remain unaffected. Better evidence is needed on this point.

\section{Discussion}

The findings reported here are of interest first because they throw new light on the question of how contractions of the vascular ampullae are coordinated, secondly because they reveal the existence of a capability for coordination of protective responses hitherto unrecognized in ascidian colonies, and finally for the interest attaching to a new case of a conducting epithelium.

\section{Coordination of ampullae}

The findings make it clear that the ampullae are coordinated by electrical impulses. NP bursts always accompany ampullar contractions, and are phase locked to the contraction cycle. Alterations in the ampullar rhythm due to stimulation or injury, for example, are faithfully mirrored in the changed pattern of electrical impulses. The rhythm, and accompanying NP burst pattern, is shown by small groups of ampullae isolated from parts of the colony containing zooids, showing that the peripheral vascular system generates the rhythm and provides the coordinating pathway for the contractions. The observed conduction velocity of $c a .2 \mathrm{~cm}$ $\mathrm{s}^{-1}$ though slow compared with most nervous and non-nervous conduction suffices to keep large colonies up to and beyond $1.0 \mathrm{~cm}$ in diameter well coordinated. Conduction in the vascular epithelium may take place by direct current flow through the gap junctions shown to be present between the cells. The observation that the ampullar rhythms of two colonies come into synchrony at the moment of fusion suggests that a critical step in the self-recognition process is the ability to form gap junctions with cells derived from another oozooid. While the present observations clarify the problem of how the ampullae are coordinated, they still do not tell us how the ampullar rhythm is generated. The evidence suggests multiple dispersed pacemaker sites, but the identity of the cells generating the rhythm remains to be determined.

\section{Coordination of zooid responses}

A number of functions have been associated with the vascular network and ampullae of botryllids and other ascidians including respiration, circulation of metabolites, secretion of tunic and substrate adhesive, and elimination of cells liberated by degenerative processes (Abbott, 1953; Mukai et al., 1978; Katow and Watanabe, 1978; Torrence and Cloney, 1981). During asexual reproduction in Metandrocarpa the vascular ampullae "withdraw the buds from the parental mantle and pull them over the substrate to points some distance from the parent" (Abbott, 1953). Whether 
or not two botryllid colonies fuse during growth is determined by processes of selfnonself discrimination at the ampullae, which are the only contact points between the two colonies (Scofield et al., 1982; Watanabe and Taneda, 1982).

Another function can now be added to this list: the ampullae and vascular vessels provide a conduction pathway mediating defensive behavior in the zooids. Any sharp or damaging stimulus to the ampullae or connecting vessels causes siphonal retraction and closure along with ciliary arrest in nearby zooids, equivalent to the well known protective squirting of solitary sea squirts. Similar systems exist in other colonial forms, both sessile and pelagic. Most animal colonies are coordinated by nervous or non-nervous conduction pathways, sometimes by both. The closest parallels to the botryllid system are to be found in certain hydroid colonies where nonnervous impulses are conducted along the stolons interconnecting the polyps. The polyps retract protectively on receiving the excitation (reviewed by Spencer and Schwab, 1982). Colonies of some other hydroids and of bryozoans and corals are coordinated by nerves, but the responses are again protective in character (reviewed by Shelton, 1982; Thorpe, 1982).

Conducting epithelia can provide an adequate pathway for simple impulse conduction over considerable distances, but the responses they mediate are complex and labile, and at the effector end they are nearly always organized by nerves (e.g., Anderson and Bone, 1980; Mackie and Carré, 1983). In the botryllid system, there is no reason to suspect the involvement of nerves in the coordination of ampullar rhythms, but the effector responses of muscle contraction and ciliary arrest in the zooids are almost certainly organized by nerves. In every zooid two-way epithelio-

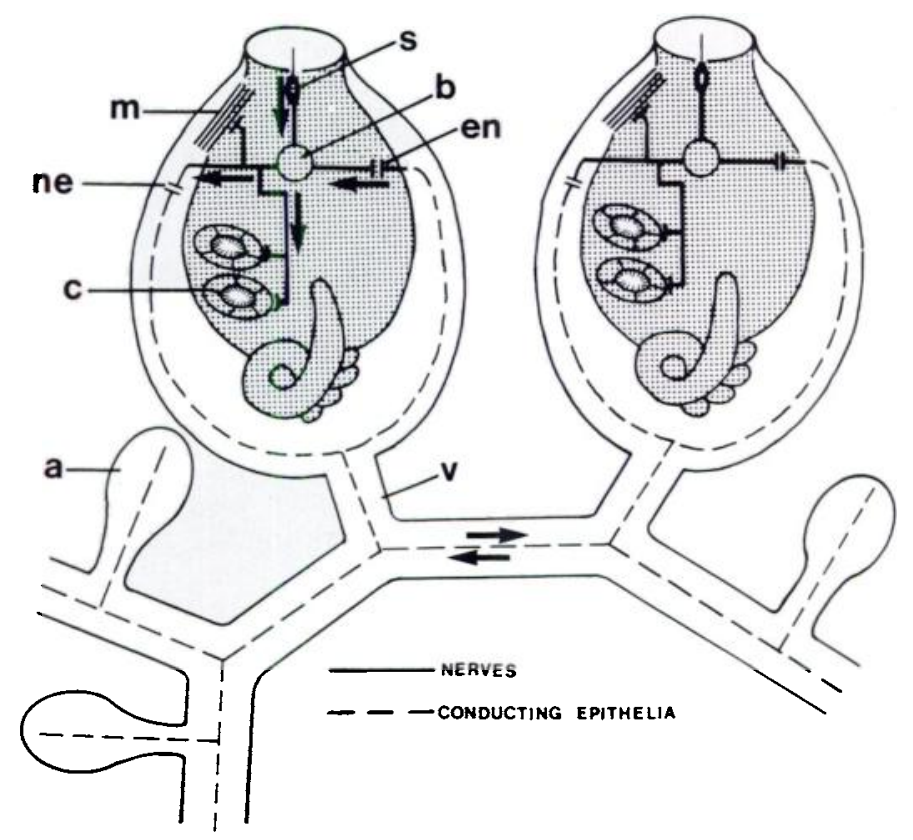

FIGURE 7. Wiring diagram of an idealized botryllid colony. Nerves are shown as solid lines, conducting epithelia as broken. a, ampulia; b, brain; c, ciliated cell of branchial sac; en, epithelio-neural transmission step; $m$, muscle in mantle wall; ne, neuro-epithelial step; $\mathrm{s}$, sensory cell; $\mathrm{v}$, vascular network. Exact locations of the transmission steps between nerves and epithelia are unknown. This diagram is designed to be understood in terms of Figure 11.23 in Bone and Mackie (1982). 
neural transmission links must exist by which NPs can excite impulses in afferent nerves and be excited in turn by efferent nerves (Fig. 7). Nothing is known about these links except that they exist. Another poorly understood feature is the mechanism responsible for incremental spread of excitation through the system. Such spread is also known in corals and hydrozoan colonies and various mechanisms have been proposed for it, but the evidence from botryllids is still too rudimentary to justify further discussion here.

\section{A new tunicate conducting epithelium}

The skins of some larvaceans and of one ascidian tadpole (Dendrodoa) are known to be capable of impulse conduction, and conducting epithelia are widespread in salps (reviewed by Anderson, 1980; Bone and Mackie, 1982). In each case, the epithelium is a covering layer, and a 'pure' conducting epithelium, not a myoepithelium. The botryllid system described in this paper is a system of blood vessels, and it is contractile in at least some regions, due presumably to the actin-like microfilaments in the lining cells. Thus it more closely resembles the tunicate heart, a myoepithelium which conducts the impulses for its own contraction (Kriebel, 1970). Like the heart, the vascular ampullae generate a rhythm. Nerves do not appear to be involved in either case. It might appear then that the contractility, rhythmicity and conducting ability are inherent properties of tunicate vascular tissue. However it is worth noting that the vascular ampullae and vessels are of epidermal origin, and that the epidermis of at least one tunicate tadpole larva is excitable. Perhaps then, the excitability of the botryllid vascular network is ontogenetically or phylogenetically linked to excitability in the larval epidermis. Whatever its origins, the system does not fit neatly into any existing category and must be classed as a new type of conducting epithelium. A study of the compound ascidian Distaplia failed to reveal any conduction between the zooids (Mackie, 1974) and the zooids in Pyrosoma colonies are not coordinated, except by serial photic auto-excitation (see Bone and Mackie, 1982). Botryllids differ from these organisms in being truly colonial: their zooids are interconnected by the vascular network. It may prove to be the case that zooid coordination by propagated impulses is only developed in those ascidian colonies which, like the botryllids, have direct vascular interconnections.

\section{ACKNOWLEDGMENTS}

The physiological work reported here was carried out during a visit by the first author to the Hopkins Marine Station, Stanford University, at Pacific Grove, California, with assistance in the form of an International Collaborative Research Grant from the National Sciences and Engineering Research Council of Canada (NSERC). This help, and the cooperation of the director and staff of the station is gratefully acknowledged. D. P. Abbott, A. Harrington, and V. L. Scofield collaborated in various phases of the work. We thank A. N. Spencer, University of Alberta, for contributing Figure 5C. The electron microscopy was carried out by the second author at the University of Victoria, with support from a NSERC operating grant.

\section{LITERATURE CITED}

ABвот, D. P. 1953. Asexual reproduction in the colonial ascidian Metandrocarpa taylori Huustman. Univ. Cal. Publ. Zool. 61: 1-78.

ANDERSON, P. A. V. 1980. Epithelial conduction: its properties and functions. Prog. Neurobiol 15: 161203. 
ANDERSON, P. A. V., AND Q. BONE. 1980. Communication between individuals in salp chains II. Physiology. Proc. Roy. Soc. B. 210: 559-574.

BANCROFT, F. W. 1899. A new function of the vascular ampullae in the Botryllidae. Zool. Anz. 22: 450462.

BERRILL, N. J. 1941. The development of the bud in Botryllus. Biol. Bull. 80: 169-184.

BERRILL, N. J. 1947. The developmental cycle of Botrylloides. Q. J. Microsc. Sci. 88: 393-408.

BONE, Q., AND G. O. MACKIE. 1982. Urochordata. Pp. 473-535 in Electrical conduction and behaviour in 'simple' invertebrates, G. A. B. Shelton, ed. Clarendon Press, Oxford.

BRUNETT, R., AND P. BURIGHEL. 1969. Sviluppo dell'apparato vascolare coloniale in Botryllus schlosseri (Pallas). Publ. Staz. Zool. Napoli 37: 137-148.

DESANTO, R.S., AND R. L. DUDLEY. 1969. Ultramicroscopic filaments in the ascidian Botryllus schlosseri (Pallas) and their possible role in ampullar contractions. J. Ultrastr. Res. 28: 259-274.

Katow, H., AND H. WATANABE. 1978. Fine structure and possible role of ampullae on tunic supply and attachment in a compound ascidian, Botryllus primigenus Oka. J. Ultrastr. Res. 64: 23-34.

KRIEBEL, M. E. 1970. Wave front analyses of pulses in tunicate heart. Am. J. Physiol. 218: 1194-1200.

MACKIE, G. O. 1974. Behaviour of a compound ascidian. Can. J. Zool. 52: 23-27.

Mackie, G. O., D. H. Paul, C. L. Singla, M. A. Sleigh, and D. E. Williams. 1974. Branchial innervation and ciliary control in the ascidian Corella. Proc. Roy. Soc. B 187: 1-35.

MACKIE, G. O., AND D. CARRE. 1983. Coordination in a diphyid siphonophore. Mar. Behav. Physiol. 9: $139-170$.

MUKAl, H., SUGIMOTO, K., AND TANEDA, Y. 1978. Comparative studies on the circulatory system of the compound ascidians Botryllus, Botrylloides and Symplegma. J. Morphol. 157: 49-78.

SABbadin, A. 1955. Osservazione sulla sviluppo, l'accrescimento, e la riproduzione di Botryllus schlosseri (Pallas) in condizioni di laboratorio. Boll. Zool. 22: 243-263.

SCOFIELD, V. L., J. M. SCHLUMPBERGER, AND I. L. WEISMANN. 1982. Colony specificity in the colonial tunicate Botryllus and the origins of vertebrate immunity. Am. Zool. 22: 783-794.

Shelton, G. A. B. 1982. Anthozoa. Pp. 203-242 in Electrical Conduction and Behaviour in 'Simple' Invertebrates, G. A. B. Shelton, ed. Clarendon Press, Oxford.

SPENCER, A. N., AND W. E. SCHWAB. 1982. Hydrozoa. Pp. 73-148 in Electrical Conduction and Behaviour in 'Simple' Invertebrates, G. A. B. Shelton, ed. Clarendon Press, Oxford.

ThORPE, J. P. 1982. Bryozoa. Pp. 393-439 in Electrical Conduction and Behaviour in 'Simple' Invertebrates, G. A. B. Shelton, ed. Clarendon Press, Oxford.

TORRENCE, S. A., AND R. A. Cloney. 1981. The thythmic contractions of the ampullar epidermis during metamorphosis of the ascidian Molgula accidentalis. Cell Tissue Res. 216: 293-312.

WATANABE, H., AND Y. TANEDA. 1982. Self and non-self recognition in compound ascidians. Am. Zool. 22: $775-782$. 